\title{
Are the civilization diseases the result of organohalogen environmental pollution?
}

\author{
Katarzyna Góralczyk ${ }^{\otimes}$ and Anna Majcher \\ Institute of Ecology and Bioethics, Cardinal Wyszynski University in Warsaw, Warsaw, Poland
}

The notion of 'civilization diseases' is used to describe certain ailments whose aetiology is difficult to explain based on the knowledge about the functioning of the body and its metabolism. Only studies at the cellular level, on biochemical changes shed light on the causes of some diseases described as civilization diseases (cancers, cardiovascular and respiratory diseases, obesity, psychomotor disorders in children and an increase in the frequency of malformations). The factors whose incontestable influence on the increase in the frequency of occurrence of various 'civilization diseases' has been proved are persistent organic pollutants, among others belonging to the group of organohalogen compounds. Among organohalogen pollutants one needs to distinguish organochlorine compounds, which have been used as pesticides, and pollution emitted by various industries such as dioxins and furans, polychlorinated biphenyls, and polybrominated organic compounds used as flame retardants and perfluoroalkylated substances, which are characterized by high chemical and thermal stability as well as high surface activity due to which they may be widely used as oleophobic and hydrophobic factors.

Key words: POPs, PCBs, PBDEs, dioxin, PFASs, civilization diseases

Received: 01 February, 2019; revised: 21 March, 2019; accepted: 15 April, 2019; available on-line: 24 May, 2019

⿶e-mail: k.goralczyk@uksw.edu.pl

Abbreviations: BDE-28, 2,4,4'-tribromodiphenyl ether; BDE-47, 2,2',4,4'-tetra-bromodiphenyl ether; BDE-100, 2,2',4,4',6-pentabromodiphenyl ether; BDE-153, 2,2',4,4',5,5'-hexabromodiphenyl ether; BDE-209, 2,2',3,3',4,4,5,5',6,6'-deca-bromodiphenyl ether; CB-28, 2,4,4'-trichlorobiphenyl; CB-52, 2,2',5,5'-tetrachlorobiphenyl; CB-77, 3,3',4,4'-tetrachloro-biphenyl; CB-81, 3,4,4',5-tetra-chlorobiphenyl; CB-101， 2,2',4,5,5'-pentachlorobiphenyl; CB-126, 3,3',4,4,5-pentachloro-biphenyl; CB-138, 2,2'3,4,4',' '-hexachlorobiphenyl; CB-153, 2,2',4,4',5,5'-hexachlorobiphenyl; CB-169, 3,3',4,4',5,5'-hexa-chlorobipheny; CB-180, 2,2',3,4,4',5,5'-heptachlorobiphenyl; DDT, dichlorodifenylotrichloro-etan; DDE, 1,1-dichloro-2,2-bis-(p-chlorophenyl)ethylene; DL-PCBs, dioxin-like PCBs; EDI, estimated daily intake; EDs, endocrine disruptors; FRs, flame retardants; $H Q$, hazard quotient; LOD, limit of detection; NDL, PCBs-non-dioxin-like PCBs; OCs, organochlorine pesticides; PBDEs, polybrominated diphenyl ethers; PCBs, polychlorinated biphenyls; PCDD, polychlorinated dibenzo-p-dioxin; PCDF, polychlorinated furans; PFASs, perfluoroalkylated substances; PFDA, perfluorodecanoic acid; PFDoDA, perfluorododecanoic acid; PFHxS, perfluorohexanesulfonic acid; PFNA, perfluorononanoic acid; PFOA, perfluorooctanoic acid; PFOS, perfluorooctane sulfonate; PFUnDA, perfluoroundecanoic acid; POPs, persistent organic pollutants; TEQ, toxicity equivalent; TTP, time to pregnancy

\section{INTRODUCTION}

The notion of 'civilization diseases' is used to describe certain ailments whose aetiology is difficult to explain based on knowledge about the functioning of the body and its metabolism. Only studies at the cellular level, on biochemical changes shed light on the causes of some diseases described as civilization diseases (cancers, cardiovascular and respiratory diseases, obesity, psychomotor disorders in children and an increase in the frequency of malformations or neurodegenerative diseases). For example, in recent years mental and behavioural disorders have increased by more than 37\% (Parkinson's disease increased by $75 \%$, Alzheimer's disease doubled, autism increased by $30 \%$ and attention deficit hyperactivity disorder (ADHD) increased by 16\%) (WHO, 2012a; Zeliger, 2013).

The factors whose incontestable influence on the increase in the frequency of occurrence of various 'civilization diseases' has been proved by numerous studies are persistent organic pollutants (POPs), among others belonging to the group of organohalogen compounds. They have been the subject of increasing anxiety for many years, especially in the context of possible biological exposure, including internal exposure coming from releasing compounds collected in an organism. All those compounds the World Health Organization (WHO) has classified as endocrine disruptors (EDs), which are the substances affecting the hormonal balance of an organism (WHO, 2012a).

Among organohalogen POPs one needs to distinguish organochlorine compounds, which have been used as pesticides (OCs), and pollution emitted by various industries such as dioxins (PCDDs) and furans (PCDFs), polychlorinated biphenyls (PCBs), and polybrominated organic compounds used as flame retardants (FRs) and perfluoroalkylated substances (PFASs), which are characterized by high chemical and thermal stability as well as high surface activity due to which they may be widely used as oleophobic and hydrophobic factors (Góralczyk et al., 2015; WHO, 2012a). Due to their physic-chemical similarities, interaction with various environmental elements, including the human organism, the ability to accumulate in organisms on different levels of the trophic pyramid, toxicological characteristics and a wide application in various aspects of life, they are, individually or collectively, a subject of various research in order to reveal how they affect the human organism and to assess the risk to human beings, especially their health (Barr et al., 2007; Chevier et al., 2010; Costa \& Grordano, 2007; Meijer et al., 2007; Tan et al., 2009).

Numerous research showed that food, especially of animal origin, including fish and seafood, is the main source of exposure for the human organism (Darnerud et al., 2006; Domingo, 2004; Frederiksen et al., 2009; Knutsen et al., 2011; Struciński et al., 2013). Table 1 presents POPs content in selected food products. For infants and young children, the group most sensitive to these xenobiotics, an important source is breast milk (Table 2), as 
Table 1. Levels of selected POPs in the food (EFSA, 2010; EFSA, 2011; EFSA, 2012)

\begin{tabular}{|c|c|c|c|c|c|c|c|c|}
\hline Products & CB-153* & $\Sigma \mathrm{PCBs}$ & $\mathrm{BDE}-47^{* *}$ & BDE-209*** & $\Sigma$ PBDEs & $\mathrm{PFOA}^{* * * *}$ & PFOS**** & $\Sigma$ PFASs \\
\hline \multicolumn{9}{|l|}{$\left[\mu \mathrm{g} \times \mathrm{kg}^{-1}\right]$} \\
\hline Meat and meat products & 1.28 & 3.74 & 0.02 & 0.06 & 0.16 & 1.19 & 29.75 & 32.49 \\
\hline Muscle meat fish and fish products & 46.31 & 123.20 & 1.31 & 0.22 & 2.32 & 0.39 & 2.20 & 6.52 \\
\hline Raw milk and dairy products incl. butter & 3.17 & 9.20 & 0.02 & 0.07 & 0.15 & 0.06 & 0.06 & 0.79 \\
\hline Vegetable oils and fats & 0.95 & 3.21 & 0.13 & 0.75 & 1.26 & 0.16 & 0.42 & 0.86 \\
\hline Fruits, vegetables and cereals & 0.02 & 0.08 & 0.02 & 0.14 & 0.15 & 0.05 & 0.06 & 2.03 \\
\hline Infant and baby food & 1.86 & 5.65 & 0.21 & 0.12 & 0.44 & N.D. & N.D. & 0.60 \\
\hline
\end{tabular}

N.D. not determined and no data; ${ }^{*} \mathrm{CB}-153$, congener from PCBs group treated as a biomarker of exposure to the whole group of PCBs; ${ }^{*} \mathrm{BDE}-47$, congener from PBDEs group treated as a biomarker of exposure to the whole group of PBDEs and occurs at the highest concentrations in the biological material; ***BDE-209, congener from PBDEs group treated as a biomarker of exposure and occurs at the highest concentrations in house dust; ***PFOA and PFOS, representatives of whole group of PFASs, which occur in the highest concentrations in environmental samples, food and biological material

Table 2. Levels of selected PCBs and PBDEs in the breast milk from different countries [ng $x \mathbf{g}^{-1}$ fat]

\begin{tabular}{|c|c|c|c|c|c|c|c|c|c|}
\hline Country & CB-28 & CB-52 & CB-101 & CB-138 & CB-153 & CB-180 & $\Sigma N D L-P C B s$ & $\Sigma D L-P C B s$ & Ref. \\
\hline Belgium & 0.88 & 0.23 & 0.39 & 18.70 & 32.20 & 17.20 & 70.20 & N.D. & Croes, 2012 \\
\hline Croatia & 5.20 & 6.40 & 0.90 & 19.33 & 26.15 & 11.21 & 78.71 & $<\mathrm{LOD}$ & $\begin{array}{l}\text { Klinčić, 2014; } \\
\text { Klinčić, } 2016\end{array}$ \\
\hline Czech Republic & 2.50 & 2.50 & 1.50 & 132.00 & 182.00 & 137.00 & 457.50 & N.D. & Miceš, 2012 \\
\hline France & 6.00 & ND & 10.20 & 54.10 & 59.00 & 35.60 & 166.80 & N.D. & Fängström, 2005 \\
\hline Germany & ND & ND & ND & 51.00 & 81.00 & 42.00 & 174.00 & 0.096 & Wittsiepe, 2007 \\
\hline The Netherlands & 0.79 & 0.17 & 0.19 & 10.70 & 16.00 & 10.70 & 39.08 & N.D. & Čechová, 2017 \\
\hline Norway & 2.32 & 0.33 & 0.72 & 32.11 & 44.86 & 20.73 & 101.77 & N.D. & Čechová, 2017 \\
\hline Poland & N.D. & N.D. & 16.90 & 23.60 & 39.80 & 26.10 & 106.40 & N.D. & Hernik, 2013 \\
\hline Russia & 3.00 & 0.93 & 3.00 & 56.33 & 64.66 & 21.00 & 148.92 & N.D. & Poldera, 2008 \\
\hline United Kingdom & 2.0 & ND & ND & 37.00 & 49.00 & 25.00 & 113.00 & N.D. & Pratt, 2012 \\
\hline China & 5.37 & 0.20 & 0.37 & 10.97 & 8.89 & 1.94 & 27.74 & 9.00 & Shen, 2012 \\
\hline USA & ND & ND & 5.41 & 11.40 & 19.80 & 9.46 & 46.07 & N.D. & She, 2005 \\
\hline Country & BDE-28 & & BDE-47 & & BDE-100 & BDE-153 & & ¿PBDEs & Ref. \\
\hline Denmark & 0.19 & & 1.99 & & 0.45 & 1.20 & & 3.00 & Antignac, 2016 \\
\hline Finland & 0.33 & & 3.12 & & 0.42 & 0.77 & & 4.64 & Antignac, 2016 \\
\hline France & 0.04 & & 0.43 & & 0.10 & 0.54 & & 1.09 & Antignac, 2016 \\
\hline Poland & ND & & 1.10 & & ND & 0.20 & & 1.30 & Hernik, 2011 \\
\hline China & 0.32 & & 0.49 & & 0.12 & 0.64 & & 1.57 & Shen, 2012 \\
\hline USA & ND & & 27.80 & & 5.25 & 4.79 & & 37.84 & She, 2005 \\
\hline
\end{tabular}

All results are given as a median. DL-PCBs, dioxin-like PCBs (CB-77, CB-81, CB-126, CB-169), NDL-PCBs, non-dioxin-like PCBs (CB-28, CB-52, CB-101, CB-138, CB-153, CB-180). N.D., not determined and no data, LOD, limit of determination

well as domestic dust which is an additional source of exposure to these compounds.

Biological monitoring of those compounds in human fat tissues provides information on the amounts accumulated by the individual from all the sources through their life and, potentially, what concentrations they may be exposed to in case of their release, e.g. while being on a diet or during lactation. It is commonly known that lactation, which may be considered as involuntary cleaning of the female organism is one of the most common ways of releasing the organohalogen compounds (Czaja et al., 2006; Covaci et al., 2008; Crisp et al., 1998; Fernandez et al., 2008; Hernik et al., 2014; Knutsen et al., 2011, Pulkrabova et al., 2009). Both phenomena provide information about the exposure in the past whereas the information about the size of the current exposure form external and internal (endogenous) sources may be obtained from the tests of those compounds' levels in the serum of peripheral blood or in umbilical cord blood in case of prenatal exposure (Axmon \& Rignell-Hydbom, 2006; Gari \& Grimalt, 2013; Ingelido et al., 2009; Kirman et al., 2011).

The biomonitoring of compounds adversely affecting human health is an indispensable tool for the assessment of threats resulting from environmental pollution while providing substantive grounds for risk management ( $\mathrm{Ta}-$ ble 3).

The monitoring of trends of those compounds levels in various environmental elements including the human being is particularly crucial when they are banned from 
Table 3. Levels of selected POPs in the biological material from different countries

\begin{tabular}{|c|c|c|c|c|c|c|c|c|c|c|c|c|}
\hline Country & CB-153 & $\Sigma \mathrm{PCBS}$ & $\Sigma D L-P C B s$ & BDE-47 & BDE-153 & BDE-209 & ¿PBDEs & OCs & PFOA & PFOS & $\Sigma$ PFASs & Ref. \\
\hline \multicolumn{13}{|c|}{ Fat tissue $\left[\mathrm{ng} \times \mathrm{g}^{-1}\right.$ fat] } \\
\hline France & 58.90 & 137.06 & 4.46 & 0.32 & 1.12 & N.D. & 1.59 & - & - & - & - & $\begin{array}{l}\text { Ploteau, } \\
2016\end{array}$ \\
\hline China & 5.80 & 13.50 & N.D. & 0.31 & 2.47 & N.D. & 3.05 & - & - & - & - & Lv, 2015 \\
\hline USA & 39.10 & 92.70 & N.D. & N.D. & N.D. & N.D. & N.D. & - & - & - & - & $Y u, 2011$ \\
\hline \multicolumn{9}{|c|}{ Blood/serum [ng $x \mathrm{~g}^{-1}$ fat] } & \multicolumn{4}{|c|}{ Blood/serum $\mu \mathrm{g} \times \mathrm{L}^{-1}$} \\
\hline France & 113.30 & 281.35 & N.D. & 0.18 & 0.48 & N.D. & 0.75 & $33.20 / 118.00$ & 5.07 & 24.08 & ND & $\begin{array}{l}\text { Ploteau, } \\
2016, \\
\text { EFSA, } \\
2015\end{array}$ \\
\hline Poland & 43.40 & 57.05 & 0.67 & 1.00 & 0.40 & ND & 1.40 & ND/506.30 & 2.83 & 8.42 & 14.70 & $\begin{array}{l}\text { Hernik, } \\
\text { 2013; } \\
\text { Góralczyk, } \\
\text { 2015a; } \\
\text { Góralczyk, } \\
2015 b\end{array}$ \\
\hline USA & 19.80 & 59.21 & N.D. & 20.50 & 5.69 & $<\mathrm{LOD}$ & 31.31 & $<\mathrm{LOD} / 238.00$ & 3.07 & 9.32 & 15.59 & $\begin{array}{l}\text { EFSA, } \\
2015\end{array}$ \\
\hline China & ND & N.D. & N.D. & 0.97 & 2.64 & N.D. & 3.97 & - & - & - & - & Lv, 2015 \\
\hline
\end{tabular}

All results are given as a median. $\Sigma$ PCBs, six indicator of PCBs (CB-28, CB-52, CB-101, CB-138, CB-153, CB-180); $\Sigma D L-P C B s$, dioxin-like PCBs (CB-77, CB-81, CB-126, CB-169); CB-153, congener from PCBs group treated as a biomarker of exposure to the whole group of PCBs. $\Sigma$ PBDEs, sum of BDE28, BDE-47, BDE-100, BDE-153, BDE-209), BDE-47, congener from PBDEs group treated as a biomarker of exposure to the whole group of PBDEs and occurs at the highest concentrations in the biological material, and BDE-209, congener from PBDEs group treated as a biomarker of exposure and occurs at the highest concentrations in house dust. PPFASs, sum of PFHxS, PFOS, PFOA, PFNA, PFDA, PFUnDA, PFDoDA,PFOA and PFOS, representatives of the whole group of PFASs, which occur in the highest concentrations in environmental samples, food and biological material. N.D., not determined and no data, LOD, limit of determination

use due to their toxicological properties. It applies to e.g. POPs which belong to organohalogen compounds, which have been banned (OCs for over 40 years, PCBs for 20 years, PFASs for 5 years), and, nonetheless, they are still present in the environmental samples.

Systematic knowledge about the tissue deposit levels of selected organohalogen compounds, their sources and human exposure to these compounds in comparison to the occurrence of civilization diseases can be an important tool in public health management. Therefore, the aim of the work was to review and systematize the information on the impact of the selected persistent organic pollutants on the occurrence of civilization diseases.

\section{CHARACTERISTICS AND THE EFFECTS OF CHOSEN ENVIRONMENTAL POLLUTANTS}

Historically, the first chloroorganic compounds that due to their toxicological properties were subjected to restrictions of the Stockholm Convention were organochlorine pesticides (OCs) such as DDT and its metabolites or Lindane, which were widely used in crop protection, sanitary hygiene and as veterinary drugs. Dichlorodiphenyltrichloroethane (DDT) is degraded to DDE (1,1-dichloro-2,2-bis-( $p$-chlorophenyl)-ethylene), which is the most persistent DDT metabolite. DDE (in the form of the $p, p$-DDE isomer) in the environmental samples, including the human body, occurs at the highest concentrations. In the case of DDT, as a representative of the entire OCs group, numerous studies have shown its role as a precursor of carcinogenic processes in humans (breast cancer, leukaemia, lymphomas), as well as its significant contribution to the formation of endometriosis, ovarian dysfunction, lower testosterone levels and the risk of obesity in children exposed during the perinatal period (Czaja et al., 2006; Góralczyk et al., 2015; Kirman et al., 2011). It should be mentioned that the research results have also indicated the role of organochlorine pesticides in the development of Parkinson's disease and Alzheimer's disease (WHO, 2012a; Zeliger, 2013).

Polychlorinated biphenyls (PCBs) is a group of chemicals with various numbers of hydrogen atoms substituted by chlorine atoms in both benzene rings. 209 potential PCB congeners with different toxicological properties have been identified. Some PCB congeners exhibit similar toxic effects as the so-called dioxins dioxin-like PCBs (DL-PCBs). This group of PCBs has also been included in the concept of toxicity equivalents (TEQ) when estimating the health risk when exposed to this group of compounds. PCBs are very persistent in the environment and transported over long distances by air and water currents in accordance with the concept of grasshopper which leads to global environmental pollution with this group of compounds. Numerous studies have shown the evident effect of these pollutants on the development of endometriosis, uterine fibroids, as well as thyroid and adrenal glands disorders, and reduced psychomotor and cognitive development in children. These compounds are also suspected of potentially increasing the risk of developing prostate and breast cancer as well as dysfunction of the immune system and may be the risk factors for Parkinson's disease (EFSA, 2010; Hoyer et al., 2014; Hoyer et al., 2015; Meijer et al., 2008; WHO, 2012a; Zeliger, 2013, Zheng et al., 2017).

Dioxin is a term used to describe a family of substances including polychlorinated dibenzo- $p$-dioxins (PCDD), polychlorinated dibenzofurans (PCDFs) and dioxin-like PCBs (DL-PCBs). Among 75 PCDDs, 135 PCDFs and 209 PCBs, respectively 7 PCDDs, 10 PCDFs and 12 DL-PCB congeners are characterized by high toxicity to humans. These compounds have a similar structure and are characterized by a common biochemical mechanism of action and similar toxicological properties. 
As demonstrated in numerous studies, exposure to this group of compounds in early childhood or in the prenatal period may in adulthood result in a decrease in the semen quality and increased risk of testicles cancer, as well as a gender imbalance with fewer male offspring. For these xenoestrogens, an increased risk of breast cancer and endometriosis and the prevalence of menopause at an earlier age has also been demonstrated (Darnerud et al., 2006; Struciński et al., 2013; WHO, 2012a).

Polybrominated diphenyl ethers (PBDEs) are a mixture of diphenyl esters with a different number of hydrogen atoms substituted by bromine. Because of the different substitution site and the different number of bromine atoms, there are 209 possible congeners with different toxicological properties. Like PCBs, they are transported over long distances with air and water currents. Some PBDEs are subjected to bioaccumulation and biomagnification in the food chain, and they are present in biological materials, including human tissues, excrements and excretions. Their presence in the human body has a proven adverse effect on the occurrence of certain diseases, e.g. early maturation, cryptorchidism, as well as a significant effect on the secretion of thyroid glands and cognitive disorders in developing organisms and diseases of the nervous system such as autism and ADHD (Chevier et al., 2010; Costa \& Giordano, 2007; EFSA, 2011; Meijer et al., 2008; WHO, 2012a; Zeliger, 2013; Zheng et al., 2017). Similarly to PCBs, exposure to PBDEs in ute$r o$ and during early development may cause behavioural disorders in children manifested by sexual dimorphism and learning disabilities (Costa \& Giordano, 2007; WHO, 2012a; WHO, 2012b).

Perfluoroalkylated substances (PFASs) are characterized by high chemical and thermal stability and high surface activity and thanks to these properties they are widely used as oleophobic and hydrophobic agents (EFSA, 2008; EFSA, 2012). The most frequently used and, therefore, present in various environmental samples in the largest concentrations are perfluorocoane acid (PFOA) and perfluorooctane sulfonate (PFOS) (Góralczyk et al., 2015; WHO, 2012a). Perfluorooctane (PFOA) is a fluorosurfactant that is often used as an emulsifier for the production of fluoropolymers (e.g. Teflon) and as a surfactant in various industries. Perfluorooctane sulfonate (PFOS) is a widely used synthetic surfactant that binds to liver and blood proteins in the human organism. Studies have shown that both compounds may be responsible for lowering the reproductive health of women measured by time to pregnancy (TTP), menstrual cycle disorders, as well as for low birth weight of children (EFSA, 2012; EFSA, 2015; WHO, 2012a; WHO, $2012 \mathrm{~b})$. The effect of exposure to PFAS, as in case of PCBs and PBDEs, is often the emergence of metabolic diseases, which are manifested by the occurrence of obesity at an early age, which can lead to the development of type 2 diabetes. In this case, scientists have no clear opinion on the order of emergence of these diseases, i.e. whether obesity causes the appearance of a coexisting disease - diabetes or vice versa (EFSA, 2012; Góralczyk et al., 2015b; Hoyer et al., 2014; WHO, 2012a).

\section{CONCLUSIONS}

Using a holistic approach to attempt to describe the relations between the exposure to a variety of different risk factors and response of an organism at the same time, is one of the most serious challenges for the public health. According to the above information, the following conclusions can be made:
Organochlorine pesticides (OCs) are constantly present in the human fat tissue despite the ban on its use since the 80s. Also, PCBs, which were included into socalled 'Dirty Dozen' group by Stockholm Convention and have been banned since the beginning of the $90 \mathrm{~s}$ are still present in the human fat tissue. The presence of those compounds in the organism is related to the internal exposure which is carefully monitored by scientists in the aspect of cumulative risk for toxic effects.

OCs, PCBs and PFASs substances are also detected in human peripheral blood serum, which means that the constant exposure to those compounds is still significant. The exposure may be both external, due to the contact with the polluted environment, including food, and internal, due to the tissue deposits' release.

Breast milk, which is the best and healthiest baby food that provides a number of benefits, including the psychological ones, also contains anthropogenic pollutants released from the female organism. In the majority of cases, those pollutants may belong to endocrine active substances (Eds), particularly dangerous during the development of the infant's hormonal system. Therefore, it is justified to check mother milk for the concentration of POPs, including chloro-, bromo- and fluorinated compounds if during the baby's development alarming symptoms are observed. The decision to continue breastfeeding ought to be taken on the basis of the tests.

The postnatal exposure in case of persistent organic pollutants from breast milk intake is in some cases dangerously high, which is showed by a very small safety margin for $p, p$ '-DDE intake from breast milk which was assessed on the basis of Estimated Daily Intake (EDI).

The levels of OCs, PCBs and PBDEs in the cord blood have proved that the exposure to those compounds is present also in the prenatal period.

In peripheral blood of women and men the markers of exposure to anthropogenic POPs from the group of organohalogen compounds such as OCs, PCBs and PFASs were discovered.

The results of the biomonitoring have shown the constant presence of those compounds in the human organism, which calls for a necessity to provide proper tools to predict the health risk to people as far as non-professional exposure to environmental pollutants is concerned. Hazard Quotient (HQ) may be used as such a tool.

The conclusions presented above are based on previous studies on possible health consequences due to the constant presence of persistent organic pollutants in human biological material. Numerous toxicological works on the risk of accumulated toxicity and possible interactions between those compounds on the organism level provide worrying data and should prompt all intense activities aimed at reducing the levels of these compounds in the environment.

\section{REFERENCES}

Antignac JP, Main KM, Virtanen HE, Boquien CY, Marchand P, Venissea A, Guiffard I, Bichon E, Wohlfahrt-Veje C, Legrand A, Boscher C, Skakkebæk NE, Toppari J, Le Bizec B (2016) Country-specific chemical signatures of persistent organic pollutants (POPs) in breast milk of French, Danish and Finnish women. Environ Pol 218: 728-738. https://doi.org/10.1016/j.envpol.2016.07.069

Axmon A, Rignell-Hydbom A (2006) Estimation of past male and female serum concentration of biomarkers of persistent organochlorine pollutants and their impact on fecundability estimates. Environ Res 101: 387-394. https://doi.org/10.1016/j.envres.2005.10.005

Čechová E, Scheringer M, Seifertová M, Mikeš O, Kroupová K, Kuta J, Forns J, Eggesbø M, Quaak I, de Cock M, van de Bor M, Patayová H, Palkovičová Murínová L, Kočan A (2017) Developmental neurotoxicants in human milk: Comparison of levels and intakes in three European countries. Sci Total Environ 579: 637-645. https:// doi.org/10.1016/j.scitotenv.2016.11.046 
Chevier J, Marley KG, Bradman A, Gharbi M, Sjödin A, Eskenazi B (2010) Polybrominated diphenyl ether (PBDE) flame retardants and thyroid hormone during pregnancy. Environ Health Perspect 118: 1444-1449. https://doi.org/10.1289/ehp.1001905

Costa LG, Giordano G (2007) Developmental neurotoxicity of polybrominated diphenyl ether (PBDE) flame retardants. Neuro Toxicol 28: 1047-1067. https://doi.org/10.1016/j.neuro.2007.08.007

Covaci A, Voorspoels S, Roosens L, Jacobs W, Blust R, Neels H (2008) Polybrominated diphenyl ethers (PBDEs) and polychlorinated biphenyls (PCBs) in human liver and adipose tissue samples from Belgium. Chemosphere 73: 170-175. https://doi.org/10.1016/j. chemosphere.2008.02.059

Croes K, Colles A, Koppen G, Govarts E, Bruckers E, van de Mieroop L, Nelen V, Covaci A, Dirtu AC, Thomsen C, Haug LS, Becher G, Mampaey M, Schoeters G, van Larebeke N, Baevens W (2012) Persistent organic pollutants (POPs) in human milk: A biomonitoring study in rural areas of Flanders (Belgium). Chemosphere 89: 988994. https://doi.org/10.1016/j.chemosphere.2012.06.058

Czaja K, Hernik A, Góralczyk K, Strucinski P, Jönsson BAG, Wojtyniak B, Ludwicki JK (2006) Age as an important factor contributing to blood concentrations of p,p-DDE and PCB-153 in men and women at reproductive age. Acta Toxicol 14: 95-104

Darnerud PO, Atuma S, Aune M, Bjerselius R, Glynn A, Petersson-Grawe K, Becker W (2006) Dietary intake estimations of organohalogen contaminants (dioxins, PCB, PBDE and chlorinated pesticides, e.g. DDT) based on Swedish market basket data. Food Chem Toxicol 44: 1597-1606. https://doi.org/10.1016/j. fct.2006.03.011

Domingo JL (2004) Human exposure to polybrominated diphenyl ethers through the diet. J Chromatography A 1054: 321-326. https:// doi.org/10.1016/j.chroma.2004.03.042

EFSA (2008) Perfluorooctane sulfonate (PFOS), perfluorooctanoic acid (PFOA) and their salts. Scientific Opinion of the Panel on Contaminants in the Food Chain. EFSA J 653: 1-131. https://doi. org/10.2903/j.efsa.2008.653

EFSA (2010) Scientific Report of EFSA. Results of the monitoring of non-dioxin-like PCBs in food and feed. EFSA J 8: 1701. https:// doi.org/10.2903/j.efsa.2010.1385

EFSA (2011) Scientific Opinion on Polybrominated diphenyl ethers (PBDEs) in food. EFSA J 9: 2156. https://doi.org/10.2903/j. efsa.2011.2156

EFSA (2012) Perfluoroalkylated substances in food: occurrence and dietary exposure. Scientific Report of EFSA. EFSA J 10: 2743. https://doi.org/10.2903/j.efsa.2012.2743

EFSA (2015) Supporting Publication:EN-724. External Scientific Report Review of the state of the art of human biomonitoring for chemical substances and its application to human exposure assessment for food safety. Choi J, Mørck TA, Polcher A, Knudsen LE, Joas A. https://doi.org/10.2903/sp.efsa.2015.EN-724

Fängström B, Strid A, Grandjean P, Weihe P, Bergman A (2005) A retrospective study of PBDEs and PCBs in human milk from the Faroe Islands. Environ Health 4: 12. https://doi.org/10.1186/1476069X-4-12

Fernandez MF, Kiviranta H, Molina-Molina JM, Laine O, Lopez-Espinosa MJ, Vartiainen T, Olea N (2008) Polychlorinated biphenyls (PCBs) and hydroxyl-PCBs in adipose tissue of women in Southeast Spain. Chemosphere 71: 1196-1205. https://doi.org/10.1016/j.chemosphere.2007.09.064

Frederiksen M, Vorkamp K, Thomsen M, Knudsen LE (2009) Human internal and external exposure to PBDEs - a review of levels and sources. Int J Hyg Environ Health 212: 109-134. https://doi. org/10.1016/j.ijheh.2008.04.005

Góralczyk K, Struciński P, Wojtyniak B, Rabczenko D, Lindh ChH, Jönsson BAG, Toft $G$, Lenters V, Czaja K, Hernik A, Bonde JP, Pedersen HS, Zvyezday V, Ludwicki JK (2015a) Is the fact of parenting couples cohabitation affecting the serum levels of persistent organohalogen pollutants? Int J Hyg Environ Health 218: 392-400. https://doi.org/10.1016/j.ijheh.2015.03.005

Góralczyk K, Pachocki K, Hernik A, Struciński P, Czaja K, Lindh ChH, Jönsson BAG, Lenters V, Korcz W, Minorczyk M, Matuszak M, Ludwicki JK (2015b) Perfluorinated chemicals in blood serum of inhabitants in central Poland in relations to gender and age. Sci Total Environ 532: 548-555. https://doi.org/10.1016/j.scitotenv.2015.06.050

Hernik A, Góralczyk K, Struciński P, Czaja K, Kucharska A, Korcz W, Snopczyński T, Ludwicki JK (2011) Polybrominated diphenyl ethers, polychlorinated biphenyls and organochlorine pesticides in human milk as marker sof environmental exposure to these compounds. Ann Agric Environ Med 18: 113-118

Hernik A, Góralczyk K, Struciński P, Czaja K, Korcz W, Minorczyk M, Ludwicki JK (2013) Polybrominated diphenyl ethers and polychlorinated biphenyls in cord blood from women in Poland. Chemosphere 93: 526-531. https://doi.org/10.1016/j.chemosphere.2013.06.045

Hoyer BB, Ramlau-Hansen CH, Henriksen TB, Pedersen HS, Góralczyk K, Zviezdai V, Jonsson BA, Heederik D, Lenters V, Vermeulen R, Bonde JP, Toft G (2014) Body mass index in young school age children in relation to organochlorine compounds in early life: a prospective study. Int J Obes 38: 919-925. https://doi.org/10.1038/ ijo. 2014.58

Høyer BB, Ramlau-Hansen CH, Pedersen HS, Góralczyk K, Chumak L, Jönsson BAG, Bonde JP, Toft G (2015) Motor development following in utero exposure to organochlorines: a follow-up study of children aged 5-9 years in Greenland, Ukraine and Poland. BMC Public Health 15: 146-156. https://doi.org/10.1186/s12889-0151465-3

Ingelido AM, Abballe A, Marra V, Valentini S, Ferro A, Porpora PG, De Felip E (2009) Serum concentration of beta-hexachlorocyclohexane in group of Italian general population: a human biomonitoring study. Ann Ist Super Sanita 45: 401-408

Klinčić D, Herceg Romanić S, Matek Sarić M, Grzunov J, Dukić B (2014) Polychlorinated biphenyls and organochlorine pesticides in human milk samples from two regions in Croatia. Environ Toxicol Phar 37: 543-552. https://doi.org/10.1016/j.etap.2014.01.009

Kirman ChR, Aylward LL, Hays SM, Krishnan K, Nong A (2011) Biomonitoring equivalents for DDT/DDE. Regulatoru Toxicol Pharmacol 60: 172-180. https://doi.org/10.1016/j.yrtph.2011.03.012

Knutsen HK, Kvalem HE, Haugen M, Meltzer HM, Brantsaeter AL, Alexander J, Päpke O, Liane VH, Becher G, Thomsen C (2011) Sex, BMI and age in addition to dietary intakes influence blood concentrations and congeners profiles of dioxins and PCBs. Mol Nutr Food Res 55: 772-782. https://doi.org/10.1002/mnfr.201000243

Meijer L, Bronwer B, de Jong FH, Bergman A, Sauer PJ (2008) Influence of prenatal exposure to selected organohalogens on infant sexual and neurological development. Organohalog Compd 70: 658-661

Mikeš O, Čupr P, Kohút L, Cerna M (2012) Fifteen years of monitoring of POPs in the breast milk, Czech Republic, 1994-2009: trends and factors. Environ Sci Pollut 19: 1936-1943. https://doi. org /10.1007/s11356-012-0798-z

Polder A, Thomsen C, Lindström G, Løken KB, Skaare JU (2008) Levels and temporal trends of chlorinated pesticides, polychlorinated biphenyls and brominated flame retardants in individual human breast milk samples from Northern and Southern Norway. Chemosphere 73: 14-23. https://doi.org/10.1016/j.chemosphere.2008.06.002

Pratt IS, Anderson WA, Crowley D, Daly SF, Evans RI, Fernandes AR, Fitzgerald M, Geary MP, Keane DP, Malisch R, McBride J, Morrison JJ, Reilly A, Tlustos C (2012) Polychlorinated dibenzo-p-dioxins (PCDDs), polychlorinated dibenzofurans (PCDFs) and polychlorinated biphenyls (PCBs) in breast milk of first-time Irish mothers: Impact of the 2008 dioxin incident in Ireland. Chemosphere 88: 865-872. https://doi.org/10.1016/j.chemosphere.2012.03.095

Pulkrabova J, Hradkova P, Hajslova J, Poustka J, Napravnikova M, Polacek V (2009) Brominated flame retardants and other organochlorine pollutants in human adipose tissue samples from the Czech Republic. Environ Int 35: 63-68. https://doi.org/10.1016/j. envint.2008.08.001

She J, Holden A, Sharp M, Tanner M, Williams-Derry C, Hooper K (2005) PBDEs greater than PCBs in $30 \%$ of breast milk samples from the Pacific Northwest. Dioxin 2005.

Shen H, Ding G, Wu Y, Pan G, Zhou X, Han J, Li J, Wen S (2012) Polychlorinated dibenzo-p-dioxins/furans (PCDD/Fs), polychlorinated biphenyls (PCBs), and polybrominated diphenyl ethers (PBDEs) in breast milk from Zhejiang, China. Environ Int 42: 84-90. https://doi.org/10.1016/j.envint.2011.04.004

Struciński P, Piskorska-Pliszczyńska J, Maszewski S, Góralczyk K, Warenik-Bany M, Mikołajczyk S, Czaja K, Hernik A, Ludwicki JK (2013) PCDD/Fs and DL-PCBs intake from fish caught in Polish fishing grounds in the Baltic Sea - Characterizing the risk for consumers. Environ Int 56: 32-41. https://doi.org/10.1016/j.envint.2013.03.002

Tan J, Loganath A, Chong YS, Obbard JP (2009) Exposure to persistent organic pollutants in utero and related maternal characteristics on birth outcomes: A multivariate data analysis approach. Chemosphere 74: 428-433. https://doi.org/10.1016/j.chemosphere.2008.09.045

WHO (2012a) State of the science of endocrine disrupting chemicals.

WHO (2012b) Endocrine disrupters and child health - Possible developmental early effects of endocrine disruptors on child health.

Wittsiepe J, Furst P, Schrey P, Lemm F, Kraft M, Eberwein G, Winneke $G$, Wilhelm M (2007) PCDD $/ F$ and dioxin-like PCB in human blood and milk from German mothers. Chemosphere 67: S286S294. https://doi.org/10.1016/j.chemosphere.2006.05.118

Zeliger HI (2013) Exposure to lipophilic chemicals as a cause of neurological impairments, neurodevelopmental disorders and neurodegenerative diseases. Interdiscip Toxicol 6: 103-110. https://doi. org/10.2478/intox-2013-0018

Zheng J, He Ch-T, Chen S-J, Yan X, Guo M-N, Wang M-H, Yu Y-J, Yang Z-Y, Mai B-X (2017) Disruption of thyroid hormone (TH) levels and TH-regulated gene expression by polybrominated diphenyl ethers (PBDEs), polychlorinated biphenyls (PCBs), and hydroxylated PCBs in e-waste recycling workers. Environ Int 102: 133-148. https://doi.org/10.1016/j.envint.2017.02.009 